Association for Information Systems AIS Electronic Library (AISeL)

ECIS 2004 Proceedings

European Conference on Information Systems

2004

\title{
Perceived Risk and Trust Associated with Purchasing at Electronic Marketplaces
}

Tibert Verhagen

Vrije University, tverhagen@feweb.vu.nl

Yao-Hua Tan

Free University Amsterdam, ytan@feweb.vu.nl

Follow this and additional works at: http://aisel.aisnet.org/ecis2004

\section{Recommended Citation}

Verhagen, Tibert and Tan, Yao-Hua, "Perceived Risk and Trust Associated with Purchasing at Electronic Marketplaces" (2004). ECIS 2004 Proceedings. 159.

http://aisel.aisnet.org/ecis2004/159

This material is brought to you by the European Conference on Information Systems (ECIS) at AIS Electronic Library (AISeL). It has been accepted for inclusion in ECIS 2004 Proceedings by an authorized administrator of AIS Electronic Library (AISeL). For more information, please contact elibrary@aisnet.org. 


\title{
PERCEIVED RISK AND TRUST ASSOCIATED WITH PURCHASING AT ELECTRONIC MARKETPLACES
}

Verhagen, Tibert, Vrije Universiteit Amsterdam, De Boelelaan 1105, 1081 HV Amsterdam, The Netherlands, tverhagen@feweb.vu.nl

Tan, Yao-Hua, Vrije Universiteit Amsterdam, De Boelelaan 1105, 1081 HV Amsterdam, The Netherlands, ytan@feweb.vu.nl

\begin{abstract}
Understanding consumer behavior is of vital importance to consumer oriented e-business models today. In this paper we report on a study into the relationships between consumer perceptions of risk and trust and the intention to purchase at a C2C electronic marketplace. Distinguishing for electronic marketplace settings is that consumer behavior is subject to perceptions of both selling party and the institutional structures of the intermediary operating the system. Building upon the well-established literature of trust we consider the concepts of institutional trust and party trust. We extend this categorization by introducing the concepts of institutional risk and party risk. Next, we adopt the process of measurement instrument development as put forward by Churchill (1979). We develop measurement instruments for institutional trust (4 items), institutional risk (5 items) and party risk (4 items). All measurement scales contain acceptable alpha's and are unidimensional. An empirical study is applied to explore the relationships between the risk and trust types and consumer purchase intention. The results reveal significant, direct effects of party trust and party risk. Second order effects of institutional trust and institutional risk are investigated and reported. The paper concludes with general observations and recommendations for further research.
\end{abstract}


The research objective of this paper is to explore the relationships between perceptions of risk and trust associated with purchasing from sellers at an electronic marketplace (EM) and consumer purchase intentions. Lowering the perceived risks associated with online transaction as well as maintaining transaction trust are vital keys to attracting consumers and retain customers (Tan and Thoen, 2000, 2002). Due to the lack of physical presence visitors of EMs cannot experience the products by, for example, touching, feeling or smelling them. Furthermore, consumers are not able to visit the EM to reassure appropriate settlement should they be dissatisfied for any reason (e.g. payment problems, product failure). This implies consumers depend on perceptions of the EM to assess the trustworthiness and perceived risks associated with the purchase before completing an online transaction.

As opposed to 'traditional' consumer- seller relationships, however, in a mediated environment consumers not only trust in perceptions of the seller when engaging in purchase behavior but also rely on characteristics of the intermediary. In the trust literature (e.g. Pavlou, 2002) this has been acknowledged by separating institutional trust from party trust. Institutional trust refers to the trustworthiness of the intermediary operating the system. It reflects perceptions of security due to the presence of guarantees, regulations or other structures that are introduced by these institutions. Party trust concerns perceptions of trust in the counterpart of a transaction. With respect to purchasing at EMs, the direct object of party trust is the party selling the products. The relationships between institutional trust and party trust and purchase behavior at EMs have received substantial attention and are explored empirically (e.g. Pavlou and Gefen, 2002). When focusing on the closely related concept of perceived risk, however, the differences between risks associated with the intermediary operating the system versus risks associated with the selling party have been relatively unexplored. Most research today has considered risk as one construct (e.g. Jarvenpaa, Tractinsky and Vitale, 2000; Pavlou and Gefen 2002) or has explicitly been paying attention to perceived risk components (e.g. Featherman and Pavlou, 2002). We argue that, similar to the two trust types identified in the literature, purchasing at EMs is subject to two types of risk: institutional risk and party risk. Institutional risk refers to the potential failure of institutional mechanisms employed by the intermediary. The target of institutional risk is the intermediary. Party risk reflects the uncertainties that arise since one is unsure about the offers of the counterpart of the transaction and its ability and willingness to perform. The target of party risk is the selling party.

In this paper we explore the relationships between institutional trust, party trust, institutional risk and party risk and consumer intentions to purchase at an EM. We consider the theoretical background of institutional trust and party trust and introduce the concepts of institutional risk and party risk. Next, we report on first empirical exploration. We conclude with overall observations and recommendations for further research.

\section{THEORETICAL FOUNDATIONS: PERCEIVED RISK AND TRUST ASSOCIATED WITH PURCHASING AT EMS}

The vast majority of empirical works in the field of trust, perceived risk and online purchase behavior has focused on purchasing at online stores. In general, the empirical results emphasize the importance of trust and risk in explaining and predicting online purchase behavior (e.g. Jarvenpaa et al., 2000; Van der Heijden et al., 2003). Purchasing at online stores is dyadic in nature, which implies that two parties are involved in the transaction: the buyer and the seller. When studying purchase behavior at an EM, however, three parties have to be taken into account: the buyer, the seller and the intermediary operating the system. In this context, consumer purchase behavior is not only affected by risk and trust perceptions of the selling party but is also subject to perceptions of risk and trust associated with the intermediary. In this study, we focus on consumer purchase behavior at EMs. An EM is defined here 
as a web site as well as the underlying organisation and its information systems that matches buyers and sellers, facilitates the exchange of information, goods, services and payments associated with transaction, and provides an institutional infrastructure (see (Bakos, 1998)). In particular, we focus on EMs in consumer products (C2C).

In the literature, the relationships between trust and intermediaries have widely been discussed. Next to aggregating buyer demand and supplier products, facilitating the market by lowering costs and matching buyers and sellers, an important role of intermediaries is to protect buyers and sellers from opportunistic behavior of other participants by acting as agent of trust (Bailey and Bakos, 1997). In this context, the term institutional trust is used. Institutional trust, also referred to as impersonal trust (Zucker, 1986) or control trust (Tan and Thoen, 2000 \& 2002), refers to the security one feels about a situation because of guarantees, regulations, safety nets or other structures (Shapiro, 1987; McKnight, Cummings and Chervany, 1998). Institutional trust is defined as the consumer's subjective belief that favorable conditions are in place to facilitate transaction success (Pavlou and Gefen, 2002, p.669). Although many third-party intermediaries contributing to institutional trust may be present in consumer-seller relationships, this research focuses on the formal authority that manages the exchange network (cf. Pavlou and Gefen, 2002). To generate trust in the online purchase situation intermediaries verify and monitor the parties engaged, reassure enforcements in case of opportunistic behavior and take care of privacy and security of both data and transaction. Widely applied instruments include monitoring, accreditation, safeguards (e.g. contracts), regulations, structural assurances and security measures like SSL. The favorable conditions and structures offered by the intermediary allow consumers to believe that purchasing at the marketplace is trustworthy.

Whereas institutional trust concerns the intermediary as mediating 'care-taker', party trust reflects perceptions of trust in the counterpart of a transaction. The direct object of party trust, in the literature also known as interpersonal trust, is the specific other individual one trusts (McKnight and Chervany, 2002, p. 42). Following the work of Pavlou (2002), party trust is defined as the subjective belief with which consumers assess that sellers will perform potential transactions according to their confident expectations, irrespective of their ability to fully monitor them (p.218). Following the studies of Pavlou (2002) and Pavlou and Gefen (2002) the target of party trust in this study is the population of sellers at the EM.

While the trust types described above have received substantial attention in the literature, the relationships between perceived risk and consumer purchasing at EMs have been relatively unexplored. Similar to the closely related concept of trust, however, two types of risk can be identified: institutional risk and party risk.

Institutional risk, refers to risks that are caused by the failure of an institution to reduce opportunistic behavior between trading parties. In many cases institutions use specific mechanisms to reduce opportunistic behavior such as, for example, contracts or certification. Consider, for example, a contract in which a due date for payment is stipulated, but there is no penalty for overdue payment. Assuming that the sellers intended to have this penalty, the lack of this penalty is an example of careless contracting and as such an institutional risk. Another typical case of institutional risk is weak monitoring. A good contract can be made ineffective by weak monitoring. For example, if the financial auditing of a company is very sloppy, overdue payments could go unrecorded, and hence even if penalty clauses are included in the contract it these rights are not exercised, because there is no adequate record to prove it. A more interesting case of weak monitoring is the weaknesses in the earlier version of eBay's reputation system, where it was possible that two people A and B could create extreme positive ratings for each other by selling the same good between each other several times with the sole purpose of being able to give high ratings to the other person. After they build up maliciously this positive reputation, they could subsequently abuse this reputation, by selling bad goods to a third person C. Institutional risk can never be completely excluded, so many things can go wrong that it is impossible to foresee all possible future mishaps, hence perfect contracts that cover all risks are impossible. To some extent institutional risk is related to environmental risk (Ring and van de Ven, 1994; Bensaou and Venkatraman, 1996), system-dependent uncertainty (Grabner-Kraeuter, 
2002) or exogenous risk (Hirshleifer and Riley, 1979). However, by institutional risk we mean obvious omissions in institutional mechanisms that should have been noticed by the average expert in the field. Institutional risks are not restricted to weak contracts, but they can also relate to the lack of adequate security measure and technological mistakes (Grabner-Kraeuter, 2002). Hence, even though intermediaries have an important control on the security and privacy of transactions, there is a possibility for sellers or unknown parties to compromise the transaction process (Pavlou, 2003). Some typical consequences of institutional risk are theft of money, improper use of private information or credit card information by a third party. In this study we focus on the institutional risks that are caused by the intermediary between buyer and seller, in particular the facilitator of the electronic marketplace.

Party risk concerns the relational risks resulting from the trading partner. Party risk, also referred to as behavioral risk (Ring and van de Ven, 1994; Bensaou and Venkataman, 1996) or endogenous risk (Hirshleifer and Riley, 1979), refers to the uncertainties that arise because online sellers can behave opportunistically by taking advantage of the distant and impersonal nature of online transactions and the intermediaries inability to carefully monitor all transactions (Pavlou, 2003, p.77). Party risk addresses the uncertainties that arise since one is unsure about the offers of the selling party (Hirshleifer and Riley, 1979) and the seller's ability and willingness to perform (Grabner-Kraeuter, 2002). For example, sellers can include misleading product information, use false identities, ignore warranties or commit fraud. The types of risks included in party risk are financial risk because of the possibility to lose money, privacy risk because of the opportunity to disclose private information, physical risk due to potentially unsafe products and performance risk because of imperfect monitoring (Pavlou, 2003, p.77). To reduce party risk various kinds of information are offered including information about regulations and procedures, the reputation of the seller (i.e. rating systems) and privacy statements. By offering the information and services that consumer gather/demand for, consumers are able to cope with perceptions of risk (Murray, 1991).

Given the above, we arrive at the observation that consumer purchasing at EMs is subject to two types of trust (institutional trust and party trust) and two types of risk (institutional risk and party risk). Institutional trust reflects trust perceptions of the intermediary operating the system, whereas party trust refers to the trustworthiness of the sellers at an EM. Similarly, institutional risk concerns the risks associated with the intermediary operating the system, whereas party risk reflects impressions of the risks associated with the sellers at an EM. The constructs differ according to the trust or perceived risk perspective they belong to, as well as the target they refer to. The similarities and differences between the four constructs are summarized in the table below.

\begin{tabular}{|l|l|l|}
\hline & Trust & Perceived risk \\
\hline Intermediary & Institutional trust & Institutional risk \\
\hline Sellers & Party trust & Party risk \\
\hline
\end{tabular}

Table 1. Trust and risk types associated with purchasing at EMs

\section{RESEARCH METHODOLOGY}

To explore the impact of institutional trust, party trust, institutional risk and party risk on consumer purchasing, we conducted an empirical study. We addressed how and to what extent perceptions of the 
trust and risk types affect consumers' intentions to purchase at an EM. This section introduces the research model and deliberates on measurement instruments and research method.

Conceptual model

The model to be tested is depicted in figure 1 . The backbone of the model is the relationships between the attitude towards purchasing from sellers at an EM and the intention to purchase from sellers at an EM. This structure conforms to the Theory of Reasoned Action (TRA) of Ajzen and Fishbein (1980) that has extensively been applied in online consumer behavior research (e.g. Crisp, Jarvenpaa and Todd, 1997; Moon and Kim, 2001; Shim, Eastlick, Lotz and Warrington, 2001). According to the TRA, variables that are not part of the theory do not add to the predictions of intentions over and above the attitude (Fishbein and Ajzen, 1975; Ajzen and Fishbein, 1980). Research in the field of online purchasing confirms that the impact of these so called external variables is likely to be mediated by an attitudinal component (Jarvenpaa et al., 2000; Van der Heijden et al., 2003; O'Cass and Fenech, 2003). The external variables to be tested comprise the trust and risk types associated with purchasing from EMs as discussed in the previous section. This implies institutional trust, party trust, institutional risk and party risk are included. Since perceptions of trust are likely to have a positive effect on consumer attitudes towards online purchasing (Jarvenpaa et al., 2000), we expect the effects of institutional trust and party trust to be positive. Following research focussing on the relationships between perceived risk and online consumer purchasing (e.g, Jarvenpaa et al., Van der Heijden et al., 2003.), the effects of institutional risk and party risk on the attitude is expected to be negative. This results in the following combination:

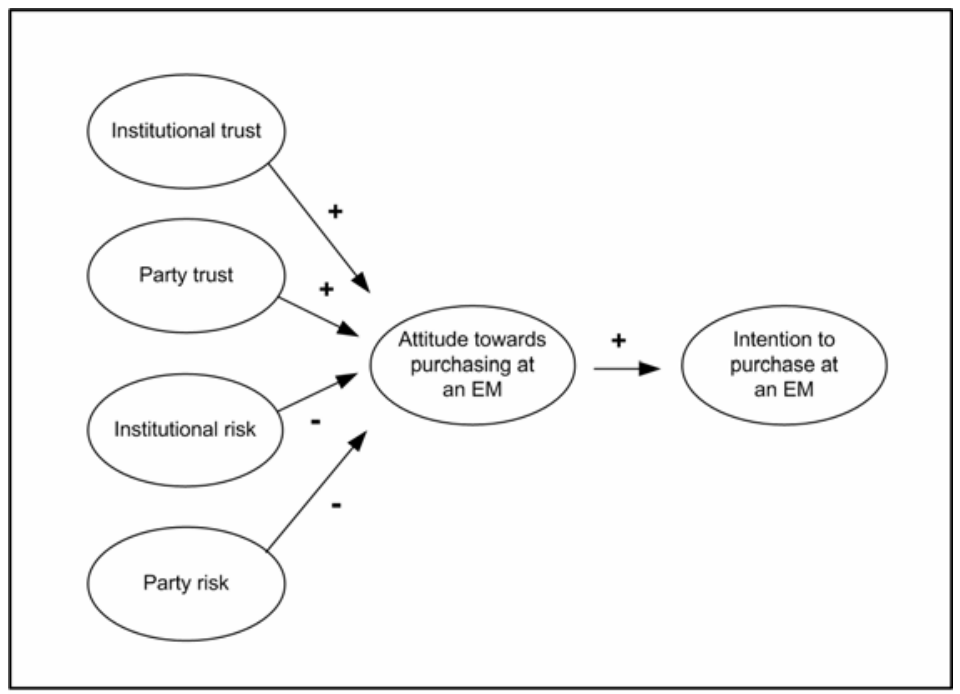

Figure 1. Research model (adapted from Ajzen and Fishbein, 1980; Tan and Thoen, 2000; Pavlou, 2002)

Measurement instruments

In order to increase reliability we operationalised each construct with multiple items. The operationalisation for the party trust construct was taken from Pavlou and Gefen (2002). Measurement instruments for institutional trust, institutional risk and party risk were, to the best of our knowledge, lacking. Following calls from Straub (1989) and Boudreau, Gefen and Straub (2001) to increase efforts on the reliability and validation of the instruments used in IS research, we built upon the measurement development process as put forward by Churchill (1979). First, a literature study was 
applied to gather a sample of items with potential validity concerning the three constructs. These items were derived from the trust and risk literature (Stone and Grønhaug, 1993; Agarwal and Teas, 2001; Grabner-Kraeuter, 2002; McKnight et al, 2002; Pavlou and Gefen, 2002; Pavlou, 2003) and were part of several trust and risk measurement instruments. We then undertook a series of focus group sessions with a sample of 10 people. Two of the participants were electronic commerce practitioners working for a well-known electronic marketplace. The remaining eight included IS faculty (six) and marketing faculty (two) from an academic institution. In the focus groups, the participants were asked to comment on the applicability of the items for each of the constructs, and to propose new items. This resulted in a draft questionnaire containing 11 items for institutional trust, 10 items for institutional risk and 10 items for party risk. The operationalisation for the attitude towards purchasing at an EM and the intention to purchase at an EM were taken from from Van der Heijden et al, 2003 who slightly modified the scales from Jarvenpaa et al. (2000). We did make some minor modifications, including the wording of the items to make them applicable for an electronic marketplace context. Next, all items were translated into Dutch, resulting in a final questionnaire.

Sample

To purify the measures and to address reliability and validity of the measures, we conducted an online survey with a student sample. This sample consisted of undergraduate students taking a mandatory core information systems course in the economics curriculum. Each student was notified in class of an assignment to study the website of the Dutch version of the electronic marketplace eBay (www.eBay.nl) and the URL to a web-based questionnaire. The assignment focused on the purchase of a laptop, a purchase often perceived as risky due to the complexity and expensiveness of the product (Stone and Grønhaug, 1993). It is conceivable that the purchase of a laptop at an EM is subject to perceptions of risk, as well as to the closely related concept of trust. The web-based questionnaire could be completed both at home or on the campus. For their participation, the students were offered a research point that would be added to the grade of their final exam. The survey was conducted from the $6^{\text {th }}$ up to and including the $10^{\text {th }}$ of October 2003.

\section{$4 \quad$ RESULTS}

Sample demographics

Eventually 167 students participated in our study. 64.7\% of the respondents were men. $35.3 \%$ were women. The vast majority of the sample consisted of experienced Internet users, most of them having experience with online shopping as well. 115 students (68.9\%) reported to have purchased a product on the Web one or more times. 44 students (26.3\%) purchased four or more times on the Web and can be considered as experienced Internet shoppers. This implies that the study is biased towards young, college educated, experienced Internet buyers. On the other hand, $96.4 \%$ of the respondents never bought a product at the eBay.nl website. Consequently, the results of the study are biased towards initial purchase intention as opposed to repeat purchase intention.

Reliability and validity

Exploratory factor analysis was used to explore whether the items measured one and only one construct. For the institutional trust, institutional risk and party risk constructs, we dropped a number of items to keep the measurement scales unidimensional. The sample met the thresholds for sampling adequacy (overall MSA 0.82, Bartlett's test of sphericity $=1857, \mathrm{p}<.001$ ). The data suggested convergent and discriminant validity since all factor loadings loaded higher on their own factor then on the others. 
Table 2 displays the Cronbach alphas for the constructs, all exceeding the 0.60 treshhold for exploratory research (Nunally, 1967) as well as the 0.70 standard for more established research (Hair, Anderson, Tatham and Black, 1998).

\begin{tabular}{|l|l|l|}
\hline Construct & Number of items & $\begin{array}{l}\text { Cronbach alpha } \\
(\mathrm{n}=167)\end{array}$ \\
\hline Institutional trust & 4 (7 dropped) & .89 \\
\hline Party trust & 4 & .92 \\
\hline Institutional risk & 5 (5 dropped) & .86 \\
\hline Party risk & 4 (6 dropped) & .81 \\
\hline Attitude & 3 & .92 \\
\hline Intention & 4 & .82 \\
\hline
\end{tabular}

Table 2. Reliability of measurement scales. Note: see appendix A for an overview of the items

To test the predictive validity of the constructs and the conceptual model against the data, we regressed institutional trust, party trust, institutional risk and party risk on the attitude towards purchasing. The attitude was regressed on the intention to purchase at an EM. The results are depicted in the figure below.

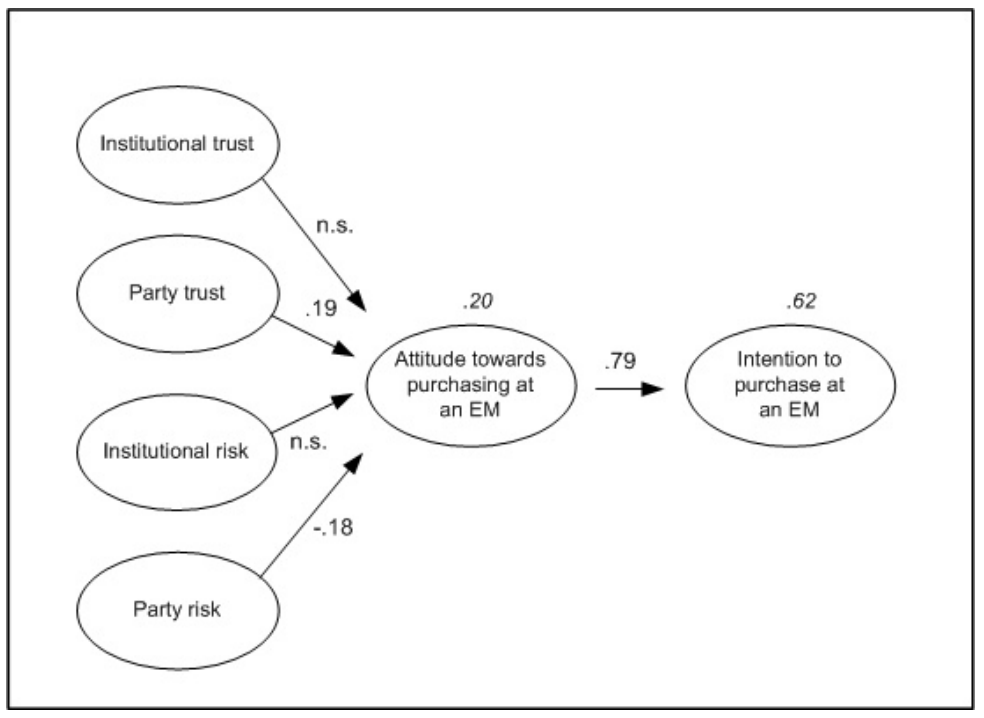

Figure 2. $\quad$ Standardized path coefficients and explained variance for the tested research model. Path coefficients are significant at $p<.05$ level. Italic parameters above the constructs refer to the amount of variance explained. n.s. refers to non significance

Two out of four components contributed to attitude towards purchasing. These are in order of relative importance party trust and party risk. The overall impact of party trust and party risk on the attitude can be labeled as 'modest'. Due to the very strong relationships between attitude and intention, a substantial amount of the impact of both variables is carried over to behavioral intention.

The two institutional components, institutional trust and institutional risk, did not directly contribute to the attitude. It is conceivable that both constructs have indirect relationships with the attitude. Recent works in the field of trust and ecommerce (e.g. McKnight et al., 2002, Pavlou, 2002) suggest that institution based trust is an important determinant of interpersonal trust (i.e. trust in specific others, trust in sellers). It is defensible to argue that perceptions of institution based structures do have an impact on the specific perceptions they refer to. Like institutional trust affecting party trust, perceptions of institutional risk are likely to influence perceptions of party risk. This was supported by 
our data. We regressed party trust and party risk on the attitude, resulting in significant betas of 0.26 and $-0.23\left(R^{2}=.17\right)$. Regression with party trust as dependent and institutional trust as independent variable revealed a significant beta of $0.57\left(R^{2}=.32\right)$. Similarly, we did detect a significant influence of institutional risk on party risk trust (beta $0.49, R^{2}=.24$ ).

\section{DISCUSSION}

We believe our research has made a number of contributions to the existing body of research.

First, we introduced the concepts of institutional risk and party risk. We believe the concepts will add to the discussion how and to what extent perceptions of EMs affect consumer purchase behavior.

Second, we developed reliable and valid new measurement instruments for the concepts of institutional risk, party risk as well as for institutional trust. We encourage researchers to apply these instruments in their own research.

Third, we empirically explored the relationships between institutional trust, party trust, institutional risk, party risk and consumer intentions to purchase at an EM. Our research results underline the importance of trust and risk perceptions of the counterpart of a transaction. Furthermore, we have shown that perceptions of the intermediary as institution are likely to affect perceptions of sellers in the EM.

The trust and risk components explained 20 percent of the variance of the attitude towards purchasing at an EM. Compared to other empirical findings in the field of trust and online consumer purchasing (e.g. Jarvenpaa et al. 2000, Van der Heijden et al, 2003), this is a low outcome. However, we believe that one should realize that consumer purchasing behaviour is the outcome of a mixture of decisionmaking processes, each of them being affected by a large number of factors. These decisions are affected by several factors, most of them falling outside the scope of those facilitating online transactions or offering their products for sale (e.g. income, culture, family, referral groups, social influence, experience). The only 'instrument' facilitators and sellers in an EM have is the online shopping environment itself. This research addressed the relationships between trust and risk characteristics of the EM as online shopping environment and the decisions where to buy (at a particular EM) and to some extent what to buy (a laptop). The impact of the trust and risk components on the decisions when to buy, how to pay and wether to buy or not have not been part of our exploration. Moreover, with respect to the decision where to buy we explicitly focused on within website choice behaviour. We did not pay attention to choice behaviour across EM websites even though the Internet enables consumer to visit and compare various websites rather effortlessly before arriving at final decision-making (O’Keefe et al., 2000). Possibly, the overall impact of the trust and risk components on consumer purchasing at EMs is more significant when the current setting is extended to other online purchase decisions, including across website choice behaviour.

Our focus on trust and risk characteristics of the EM as online shopping environment implies that online shopping system characteristics like ease-of-use, usability, enjoyment and website style have not been considered. We believe perceptions of these characteristics are likely to explain part of the remaining attitude variance. Empirical explorations in both on- and offline settings, however, have shown that shopping environments explain about 30-40 percent of the variance of consumers' attitude towards purchasing (Van der Heijden and Verhagen, 2003). This implies that, next to the trust and risk types we tested for, about 10-20 percent of the remaining variance is to be explained by other shopping system characteristics. In this context, party trust and party risk seem to explain most of the attitude variance potentially accounted for by characteristics of the shopping system.

Our research is also subject to limitations. 
An important limitation of our work is the use of the student sample. The results of our empirical explorations are biased towards young, highly educated people, most males, who are rather experienced with shopping on the Internet. This might have implications for our findings. For example, the fact that the majority of the sample was relatively experienced with online purchasing could have had a downward-biasing effect on the impact of a variable like party trust. Experience in relying on another party in online transactions possibly made trust 'less of an issue'. Future research will have to show that our findings apply in other contexts, with non-convenience samples

Another limitation concerns the validity of the research. We introduced the concepts of institutional risk and party risk. Next, we empirically explored the impact of both EM characteristics and the closely related concepts of institutional trust and party trust on consumer purchase intentions. Based on the outcomes we explored the indirect relationships of institutional trust and institutional risk. These findings, and the nature of the relationships in particular, have to be interpreted with care since more theoretical rationale and empirical exploration are needed. We plane to investigate this in future research.

\section{CONCLUSIONS AND RECOMMENDATIONS}

This research has focused on the relationships between perceptions of trust and risk in intermediaries and sellers at an EM and consumer purchase intentions. We have examined the literature on institutional trust and party trust and introduced the concepts of institutional risk and party risk. Building upon literature study and focus group interviews we developed measurement instruments for institutional trust, institutional risk and party risk. A student sample was used to address the validity of the measurement instruments. We then linked the trust and risk types to the intention to purchase at a particular EM. The results show statistical significance for party trust and party risk. Building upon existing theory, we suggested second order effects for institutional trust and institutional risk.

At least two conclusions can be derived from our research. First, perceptions of trust and risk account for a $20 \%$ proportion of the attitude towards purchasing at an EM. Obviously, other variables have to be taken into account when explaining and predicting consumer purchase behaviour at an EM. These findings have implications for both research and practice. For practice, it suggests that investing money in trust and risk issues is useful, but does not guarantee success. For research, the results underline the need for additional theoretical and empirical exploration. Other EM characteristics should be further investigated. Second, party trust and party risk have significant direct effects on the attitude towards purchasing, whereas institutional trust and institutional risk can be labelled as second order determinants. From a practical point of view, these findings suggest that investing in the intermediary as 'care-taking institution' is unlikely to directly contribute to online revenues. The fact that institutional trust and institutional risk have an impact on party trust and party risk, however, indicates that development and implementation of institutional instruments should not completely be left outside the marketing budget. For researchers, these results show that explaining and predicting online purchase behaviour in EM settings demands for taking the different actors into account. Our research results strongly support that purchasing at an EM is subject to perceptions of two different actors: the population of sellers and the intermediary operating the system. We hope splitting up the trust and risk constructs according to the actor(s) they refer to, has added to our understanding of online purchasing.

\section{References}

Agarwal, S. and Teas, R.K., "Perceived value: mediating role of perceived risk”, Journal of Marketing theory and Practice, 2001, vol. 9, no. 4, pp. 1-14.

Ajzen, I. And Fishbein, M., Understanding Attitudes and Predicting Social Behavior, Prentice Hall, Inc., Englewood Cliffs, New Jersey, 1980. 
Bailey, J. and Bakos, Y., “An exploratory study of the emerging role of electronic intermediaries”, International Journal of Electronic Commerce, 1997, 1(3), pp. 7-20.

Bakos, J.Y., "The emerging role of EM on the Internet”, Communications of the ACM, 1998, 41, 8, pp. 35-42.

Bensaou, M. and Venkataman, N., "Inter-organizational relationships and information technology: a conceptual synthesis and a research framework”, European Journal of Information Systems, 1996, 5, pp. 84-91.

Boudreau, M.C., Gefen, D. and Straub, D.W., "Validation in information

systems research: a state-of-the-art assessment," MIS Quarterly, 2001, vol. 25, no.1, pp. 1-16.

Churchill, Jr., G.A., “A Paradigm for Developing Better Measures of Marketing Constructs”, Journal of Marketing Research, 1979, vol. 16, no. 1, pp.64-73.

Crisp, C.B., Jarvenpaa, S.L. and Todd, P.A., "Individual Differences and Internet Shopping Attitudes and Intentions”, June 1997, http://ccwf.cc.utexas.edu/ crisp/Indiv_Shop.htm.

Featherman, M.S. and Pavlou, P.A., "Predicting E-services Adoption:A Perceived Risk Facets Perspective", Proceedings of the Eighth American Conference on Information Systems (AMCIS), 2002, Dallas, pp. 1034-1046.

Fishbein, M. and Ajzen, I., Belief, Attitude, Intention and Behavior: an introduction to theory and research, Addison-Wesley Publishing Company, Reading Massachusetts, 1975.

Grabner-Kraeuter, S., “The Role of Consumers’ Trust in Online-Shopping”, Journal of Business Ethics, 2002, 39, pp. 43-50.

Hair Jr., J.F., Anderson, R.E., Tatham, R.L. and Black, W.C., Multivariate data analysis, fifth edition, Prentice-Hall, Upper Saddle River, NJ, 1998.

Hirshleifer, J. and Riley, J.G., "The analytics of uncertainty and information: an expository survey, Journal of Economic Literature, 1979, vol. 17, no. 4, pp. 1375-1421.

Jarvenpaa, S.L., Tractinsky, N and Vitale, M., “Consumer Trust in an Internet store”, Information Technology and Management, 2000, vol. 1, no 1., pp. 45-71.

McKnight, D.H., Cummings, L.L. and Chervany, N.L., "Initial trust formation in new organizational relationships”, Academy of Management Review, 1998, vol. 23, no. 3, pp. 473-490.

McKnight, D.H. and Chervany, N.L., "What trust means in e-commerce customer relationships: an interdisciplinary conceptual typology”, International Journal of Electronic Commerce and Business Media, 2002, vol. 6, no. 2, pp. 35-59.

McKnight, D.H., Choudhury, V. and Kacmar, C., "The impact of initial consumer trust on intentions to transact with a web site: a trust building model”, Journal of Strategic Information Systems, 2002, vol. 11, pp. 297-323.

Moon, J-W. and Kim, Y-G., "Extending the TAM for a World-Wide-Web context”, Information and Management, 2001, 38, pp. 217-230.

Murray, K.B., “A Test of Services Marketing Theory: Consumer Information Acquisition Activities”, Journal of Marketing, 1991, vol. 55, January, pp. 10-25.

Nunnally, J.C., Psychometric Theory, second edition, McGraw-Hill, New York, 1978.

O’Cass, A. and Fenech, T., "Web retailing adoption: exploring the nature of internet users Web retailing behaviour", Journal of Retailing and Consumer Services, 2002, 10, pp. 81-94.

O'Keefe, R. M., Cole, M., Chau, P.Y.K., Massey, A., Montoya-Weiss, M. and Perry, M., "From the user interface to the consumer interface: results from a global experiment," International Journal of Human-Computer Studies, 2000, vol. 53, no. 4, pp. 611-28.

Pavlou, P.A., "Institution-based trust in interorganizational exchange relationships: the role of online B2B marketplaces on trust formation”, Journal of Strategic Information Systems, 2002, vol. 11, pp. 215-243.

Pavlou, P.A. and Gefen, D., "Building effective online marketplaces with institution-based trust”, Proceedings of the Twenty-Third International Conference on Information Systems(ICIS), December 2002, Barcelona, pp. 667-675.

Pavlou, P.A . "Consumer Acceptance of Electronic Commerce: Integrating Trust and Risk with the Technology Acceptance Model”, International Journal of Electronic Commerce, 2003, vol. 7, no. 3, pp. 69-103. 
Ring, P.S. and van de Ven, A.H., "Developing processes of cooperative inter-organizational relationships", Academy of Management Review, 1994, 19, pp. 90-118.

Roselius, T. Consumer rankings of risk reduction methods. Journal of Marketing, 1971, 35, pp. 56-61.

Shapiro, S.P. “ The social control of impersonal trust”, American Journal of Social Psychology, 1987, 93, 3, pp. 623-658.

Shim, S.; Eastlick, M.A.; Lotz, S.L. and Warrington, P., "An online prepurchase intentions model: the role of intention to search”, Journal of Retailing, 2001, 77, pp. 397-416..

Stone, R.N. and Grønhaug, K., "Perceived Risk: Further Considerations for the Marketing

Discipline”, European Journal of Marketing, 1993, vol. 27, no. 3, pp. 39-50.

Straub, D. W. (1989), "Validating instruments in MIS reseach”, MIS Quarterly, vol. 13, no. 2, pp. 147-169.

Tan, Y.H. and Thoen, W., “Towards a Generic Model of Trust for Electronic Commerce”, International Journal of Electronic Commerce, vol. 5, nr. 2, 2000, pp. 61-74.

Tan, Y-H and Thoen, W., "Formal aspects of a generic model of trust for electronic commerce", Decision Support Systems, 2002, 33, pp. 233-246.

Van der Heijden, H., and Verhagen, T., "Online store image: conceptual foundations and empirical measurement”, Information and Managament, 2003, article in press, forthcoming.

Van der Heijden, H., Verhagen, T. and Creemers, M., "Understanding online purchase intentions: contributions from technology and trust perspectives”, European Journal of Information Systems, 2003, 12, pp. 41-48.

Zucker, L., "Production of trust: institutional sources of economic structure", Research in Organization Behavior, 1986, 8, 1, pp. 53-111.

\section{Appendix A: measurement instruments}

\section{Institutional trust}

$<$ name intermediary $>$ ensures sellers are dependable

$<$ name intermediary $>$ ensures sellers are reliable

$<$ name intermediary $>$ ensures sellers are honest

$<$ name intermediary $>$ ensures sellers are trustworthy

\section{Party trust}

Sellers in this online market are in general dependable

Sellers in this online market are in general reliable

Sellers in this online market are in general honest

Sellers in this online market are in general trustworthy

\section{Institutional risk}

If I were to purchase a $<$ product $>$ through this online marketplace, I become concerned about whether $<$ name intermediary $>$

will take care of transaction security

will preclude theft of money

will protect me against fraudulent sellers.

will prevent fraudulent sellers from participating in its marketplace

will trace sellers in case of disputes

\section{Party risk}


As I consider to purchase a $<$ product $>$ through this online marketplace, I become concerned about whether sellers:

will commit fraud

will swindle

offer products that will not perform as expected

will behave opportunistic

\section{Attitude}

I am positive towards buying a $<$ product $>$ on the $<$ name $>$ website.

The thought of buying a $<$ product $>$ at the website of $<$ name $>$ is appealing to me.

I think it is a good idea to buy a $<$ product $>$ at the website of $<$ name $>$.

Intention

How likely is it that you would return to the <name $>$ website?

How likely is it that you would consider the purchase of a $<$ product $>$ at the $<$ name $>$ website in the short term?

How likely is it that you would consider the purchase of a $<$ product $>$ at the $<$ name $>$ website in the long term?

How likely is it that you would consider the purchase of a $<$ product $>$ at the $<$ name $>$ website if you need the < product $>$ ? 